\title{
Bidirectional effect of Wnt signaling antagonist DKK1 on the modulation of anthrax toxin uptake
}

\author{
QIAN LiLi ${ }^{1}$, CAI ChangZu ${ }^{1}$, YUAN PengFei ${ }^{1}$, JEONG Sun-Young $^{2}$, YANG XiaoZhou ${ }^{1}$, \\ DEALMEIDA Venita ${ }^{4}$, ERNST James ${ }^{5}$, COSTA Michael ${ }^{4}$, COHEN Stanley N. ${ }^{2,3}$ \\ \& WEI WenSheng ${ }^{1 *}$ \\ ${ }^{1}$ College of Life Sciences and State Key Laboratory of Protein and Plant Gene Research, Peking University, Beijing 100871, China; \\ ${ }^{2}$ Department of Genetics, Stanford University School of Medicine, Stanford, California 94305, USA; \\ ${ }^{3}$ Department of Medicine, Stanford University School of Medicine, Stanford, California 94305, USA; \\ ${ }^{4}$ Department of Cancer Targets, Genentech, Inc., South San Francisco, California 94080, USA; \\ ${ }^{5}$ Department of Protein Chemistry and Protein Engineering, Genentech, Inc., South San Francisco, California 94080, USA
}

Received March 4, 2014; accepted March 7, 2014; published online March 25, 2014

\begin{abstract}
LRP6, a co-receptor for the morphogen Wnt, aids endocytosis of anthrax complexes. Here we report that Dickkopf1 (DKK1) protein, a secreted LRP6 ligand and antagonist, is also a modulator of anthrax toxin sensitivity. shRNA-mediated gene silencing or TALEN-mediated gene knockout of $D K K 1$ reduced sensitivity of cells to PA-dependent hybrid toxins. However, unlike the solely inhibitory effect on Wnt signaling, the effects of DKK1 overexpression on anthrax toxicity were bidirectional, depending on its endogenous expression and cell context. Fluorescence microscopy and biochemical analyses showed that DKK1 facilitates internalization of anthrax toxins and their receptors, an event mediated by DKK1-LRP6-Kremen2 complex. Monoclonal antibodies against DKK1 provided dose-dependent protection to macrophages from killing by anthrax lethal toxin (LT). Our discovery that DKK1 forms ternary structure with LRP6 and Kremen2 in promoting PA-mediated toxin internalization provides a paradigm for bacterial exploitation of mechanisms that host cells use to internalize signaling proteins.
\end{abstract}

DKK1, anthrax toxin, LRP6, TALENs, internalization, Kremen2, receptor, Wnt

Citation: Qian LL, Cai CZ, Yuan PF, Jeong SY, Yang XZ, DeAlmeida V, Ernst J, Costa M, Cohen SN, Wei WS. Bidirectional effect of Wnt signaling antagonist DKK1 on the modulation of anthrax toxin uptake. Sci China Life Sci, 2014, 57: 469-481, doi: 10.1007/s11427-014-4646-x

Anthrax is a lethal disease caused by the combined actions of three polypeptide toxins secreted by the gram-positive bacterium, Bacillus anthracis: protective antigen (PA, $83 \mathrm{kD})$, lethal factor (LF, $90 \mathrm{kD})$, and edema factor (EF, $89 \mathrm{kD})[1,2]$. None of these proteins is individually toxic to the host, but bipartite complexes consisting of PA and LF or PA and EF, which form lethal toxin or edema toxin, respectively, initiate events that result in anthrax disease. LF is a zinc-dependent metalloproteinase that blocks the ERK, p38

*Corresponding author (email: wswei@pku.edu.cn) and Jun $\mathrm{N}$ terminus kinase (JNK) pathways [3] by cleaving and inactivating mitogen-activated protein kinase kinases (MEKs) 1-4, 6, and 7 [4-6]. EF is calmodulin-dependent adenylate cyclase that causes rapid accumulation of cAMP, leading to multiorgan failure [1,7]. Entry of EF and LF into mammalian cells requires interaction of these toxic moieties with PA, which attaches them to receptor proteins on the surface of targeted cells: tumor endothelium marker-8 (TEM8; anthrax toxin receptor 1 (ANTXR1)), capillary morphogenesis protein-2 (CMG2; anthrax toxin receptor 2 (ANTXR2)), and integrin $\beta 1$ complexes [8-10]. CMG2 is 
the principal ligand for PA in rodents [11]. As LF lethality requires dependence of targeted cells on MAPKK [5,12], which normally is observed for macrophages but not for most other cell types, FP59, a PA-binding fusion protein containing LF amino acids 1-254 and the catalytic domain of Pseudomonas aeruginosa exotoxin A commonly is employed to investigate the binding and internalization actions of PA [13,14]. For similar reasons, LFnDTA (a fusion of the PA binding domain of LF to the enzymic A chain of diphtheria toxin) [15] has also been used as a surrogate for LF. At least two other host-encoded cell proteins, low density lipoprotein receptor like protein 6 (LRP6), which has been widely studied as a co-receptor for the morphogen Wnt [16-18], and ARAP3, a GTPase implicated in PI3K signaling [19], do not directly bind to PA but can promote endocytosis of PA-complexes [19-21].

DKK1 (Dickkopf-1) is a secreted, high-affinity ligand for LRP6 that antagonizes LRP6-mediated Wnt signaling by two distinct mechanisms: (i) by interacting with LRP6, DKK1 interrupts Wnt-induced binding of LRP6 to Frizzled $(\mathrm{Fz})$, another LRP6 ligand implicated in Wnt signaling, interfering with signal transduction without affecting LRP6 internalization or degradation [22-24]; and (ii) DKK1 forms complexes with LRP6 and Kremen1 or Kremen2transmembrane proteins that trigger internalization of LRP6 and reduce LRP6 availability at cell surface for Wnt signaling $[25,26]$. It has been proposed recently that DKK1 can also inhibit Wnt signaling by blocking Wnt binding to LRP6 [27,28]. Here we report that DKK1 is a modulator of PA-mediated anthrax toxin endocytosis, and that anthrax toxin hijacks a ternary complex consisting of DKK1, LRP6 and Kremen 2 to assist with its endocytosis, further linking the developmentally-important Wnt signaling pathway to anthrax toxin internalization.

\section{Materials and methods}

\subsection{Expression constructs}

DKKI genes were obtained through PCR-amplification from human or mouse cDNA, and cloned into pIRES-hyg2 or pEF6MycHisBsd-B-based vectors for expression.

\subsection{Mammalian cell culture, transfection and lentivirus infection}

The human prostate cancer cell line M2182 was maintained in RPMI 1640 medium (Invitrogen, USA) by using supplements as described in [29]. RAW264.7 mouse macrophage, HEK293T, HeLa and BHK cell lines were cultured in DMEM (Invitrogen, USA) containing 10\% FBS. DNA transfections were performed with Polyethylenimine (PEI)-mediated method [30], FuGene6 (Roche, Switzerland) or Lipofectamin 2000 (Invitrogen, USA) according to the manufacturer's recommended protocols. Lentivirus were produced by transient transfection of HEK293T cells (PEImediated methods) by using DNAs along with packaging and VSVG envelope constructs as described [31]. Details are the same as reported [20].

\subsection{Preparation of $h D K K 1$-specific shRNAs}

Expression constructs carrying lentiviral shRNAs specifically targeting on human DKK1 gene were obtained from Openbiosystems, Inc. Stable shRNA expression in the vector of pLKO.1 was achieved in M2182 cells through viral infection followed by puromycin $\left(1 \mu \mathrm{g} \mathrm{mL}{ }^{-1}\right)$ selection. Total of five different $D K K 1$-specific shRNAs were used. Their clone IDs and targeting sequences are TRCN0000033384 (5'-CGGGAATAAGTACCAGACCAT), TRCN0000033385 (5'-CGGTTCTCAATTCCAACGCTA), TRCN00000333856 (5'-CCTGTCCTGAAAGAAGGTCAA), TRCN0000033387 (5'-GCCAGTAATTCTTCTAGGCTT), and TRCN0000033388 (5'-CCAGAAGAACCACCTTGTCTT), respectively.

\subsection{Antibodies}

Full-length His-tagged human DKK1 protein was expressed and purified from baculovirus cell supernatants, and antibodies were raised against the protein using standard hybridoma technology. Hybridoma clone supernatants were screened by ELISA and Western analysis, and seven positive clones were identified for monoclonal selection and antibody purification. The monoclonal antibody against PA was obtained from Novus Biologicals (NB 600-407) (USA). Agarose-conjugated monoclonal antibodies of c-Myc (9E10), HA (F-7) were obtained from Santa Cruz Biotechnology (USA). Peroxidase-conjugated mouse monoclonal antibody (clone 9E10) against c-Myc (11814150001) and peroxidase-conjugated mouse monoclonal antibody (clone 12CA5) against HA (11667475001) were ordered from Roche (China) Ltd. Mouse anti-tubulin mAb and horseradish peroxidase-conjugated secondary antibodies were purchased from Santa Cruz Biotechnology (USA).

\subsection{Immunofluorescence microscopy}

Chimeric LF-EGFP protein purification was the same as reported [32]. To monitor cell surface binding, cells were first treated with PA83 $\left(600 \mathrm{nmol} \mathrm{L}{ }^{-1}\right)$ for $12 \mathrm{~min}$ at $37^{\circ} \mathrm{C}$, washed, incubated with LF-EGFP $\left(200 \mathrm{nmol} \mathrm{L}^{-1}\right)$ for $2 \mathrm{~min}$ at $37^{\circ} \mathrm{C}$ and immediately washed and fixed before examined by confocal microscopy. To monitor PA/LF-EGFP internalization, cells were incubated with PA83 $\left(600 \mathrm{nmol} \mathrm{L}^{-1}\right)$ and LF-EGFP $\left(200 \mathrm{nmol} \mathrm{L}^{-1}\right)$ for $15 \mathrm{~min}$ at $37^{\circ} \mathrm{C}$, followed by confocal microscopy. Immunostaining was performed according to a standard protocol [33]. The cover slips were mounted onto slides with a mounting medium containing DAPI (Vector Laboratories, USA), and the cells were 
examined by using an LSM 710\&NLO confocal microscope (Zeiss, Germany). The detailed procedure was the same as reported [32].

\subsection{Cytotoxicity assay}

PA and LF were purchased from List Biological Laboratories, Inc., and FP59 was produced as described previously [34]. LFnDTA, a surrogate of LF consisting of the N-terminal domain of LF fused to the catalytic subunit of diphtheria toxin, was produced by using plasmid pET15b-LFNDTA (Addgene plasmid 11075) [35]. Cytotoxicity assays for M2182, HeLa, HEK293T, and BHK were performed by seeding the cells in 96-well plates (100 $\mu \mathrm{L} /$ well) at a concentration of $5 \times 10^{4}$ cells $\mathrm{mL}^{-1}$ one day prior to the toxin treatment; the cell concentration used was $1 \times 10^{5}$ cells $\mathrm{mL}^{-1}$ for $\mathrm{RAW} 264.7$ cell line. Various concentrations of PA combined with a fixed concentration of FP59 (50 ng mL ${ }^{-1}$ ) or LF (500 ng mL ${ }^{-1}$ for RAW264.7 line), or LFnDTA (50 ng mL ${ }^{-1}$ ) was added to wells, and cells were incubated at $37^{\circ} \mathrm{C}$ for 48 or $18 \mathrm{~h}$ (for RAW264.7 line). Cell viability was measured by MTT assay as described [20].

\subsection{Western blotting and co-immunoprecipitation}

Western blotting was performed essentially as described by Harlow and Lane [33] using $10 \%$ or 3\%-8\% gels (NuPAGE Novex Tris-Acetate Gels, EA0378BOX, Invitrogen, USA) for electrophoresis and standard conditions. The soluble cell proteins were quantitated using BCA protein assay kit (Pierce Biotechnology, USA). For co-immunoprecipitation assays, HEK293T cells, $48 \mathrm{~h}$ after transfection, were lysed in NP40 buffer containing a protease inhibitor cocktail (Complete Mini, Roche China, Ltd.). The lysates were centrifuged at $16000 \times g$, and the soluble fraction was immunoprecipitated with the desired antibody-conjugated agarose beads (Santa Cruz Biotechnology, USA).

\subsection{Biochemical assay of PA binding and interna- lization}

Methods were as described [20]. The concentration and its incubation time for binding assay were $1 \mu \mathrm{g} \mathrm{mL} \mathrm{m}^{-1}$ and $1 \mathrm{~h}$, respectively.

\subsection{Construction of stable knockout cell lines using TALEN technique}

The design and assembly of the two pairs of TALENs constructs used for $D K K 1$ gene-knockout were based on our own ULtiMATE protocol [36]. More specifically, the two targeting sequences for $D K K 1$ loci are 5'-TCCAACGCTATCAAG-3' for TALEN ${ }^{\mathrm{L}}$ and 5'-GCCCCGCAGCGCCGC$3^{\prime}$ for TALEN ${ }^{\mathrm{R}}$, with a spacer sequence $\left(5^{\prime}\right.$-AACCTGCCC-
CCACCGCTGG-3'). The identification and verification of gene knockout events were based on both sequencing analysis of genome PCR fragments of targeting loci and functional assay of Wnt signaling using a beta-cateninregulated promoter on the Super8XTOPflash reporter plasmid [37].

\section{Results}

\subsection{Effect of DKK1 knockdown on PA-mediated toxicity}

Earlier work has shown that reduced activity of LRP6 gene mediated by either genetic or immunological interference leads to a decrease in the cell killing by anthrax toxin and also by a surrogate toxin that is dependent on PA for endocytosis [20,21]. LRP6 was found to facilitate internalization of PA and toxin moieties bound to it in the human prostate cancer cell line M2182 and in mouse macrophage RAW264.7 cells [20]. As interference with LRP6 function decreases toxin lethality, we wished to learn whether inhibition of LRP6 function by its biological antagonist DKK1 has the converse effect. To elucidate the role of DKK1 in PA-mediated toxicity, five TRC lentiviral borne shRNAs specifically targeting the human $D K K 1$ gene (Open Biosystems, USA) were introduced individually into M2182 cells by viral infection. The effects of one such shRNA (TRCN0000033384) that corresponds to an mRNA sequence (5'-CGGGAAUAAGUACCAGACCAU) of the human $D K K 1$ gene are shown in Figure 1 for two randomly selected clones, shRNA384-2 and -6. Stable expression of the shRNA under control of the hU6 promoter resulted in both a decrease in abundance of DKK1 mRNA (Figure 1A) in M2182 cells and a decrease in DKK1 protein in the culture media (Figure 1B) to $30 \%$ and $50 \%$ of normal for the M2182/shRNA384-6 and M2182/shRNA384-2 clones, respectively. Associated with the observed decreased abundance of DKK1 mRNA and protein, was sharply increased expression of a TCF/beta-catenin-mediated reporter gene as assayed using a beta-catenin-regulated promoter on the Super8XTOPflash reporter plasmid [37] (Figure 1C), consistent with the known inhibitory role of DKK1 in Wnt signaling [38]. shRNA (TRCN0000033387) that corresponds to an mRNA sequence (5'-GCCAGUAAUUCUUCUAGGCUU) of the human $D K K 1$ gene had little effect on the abundance of $D K K 1$ mRNA (Figure 1A) or DKK1 protein (Figure 1B), and consequently had no effect on the Wnt signaling (Figure 1C). Data for one such clone (M2182/shRNA387-5) are included in this and other figures as a negative control.

Lethality mediated by PA+FP59 in M2182 clones shNRA384-2 and -6 was assessed by MTT assay [20] using a series of PA concentrations and a fixed concentration of FP59 (50 $\mathrm{ng} \mathrm{mL}^{-1}$ ). Paradoxically, given the observed 

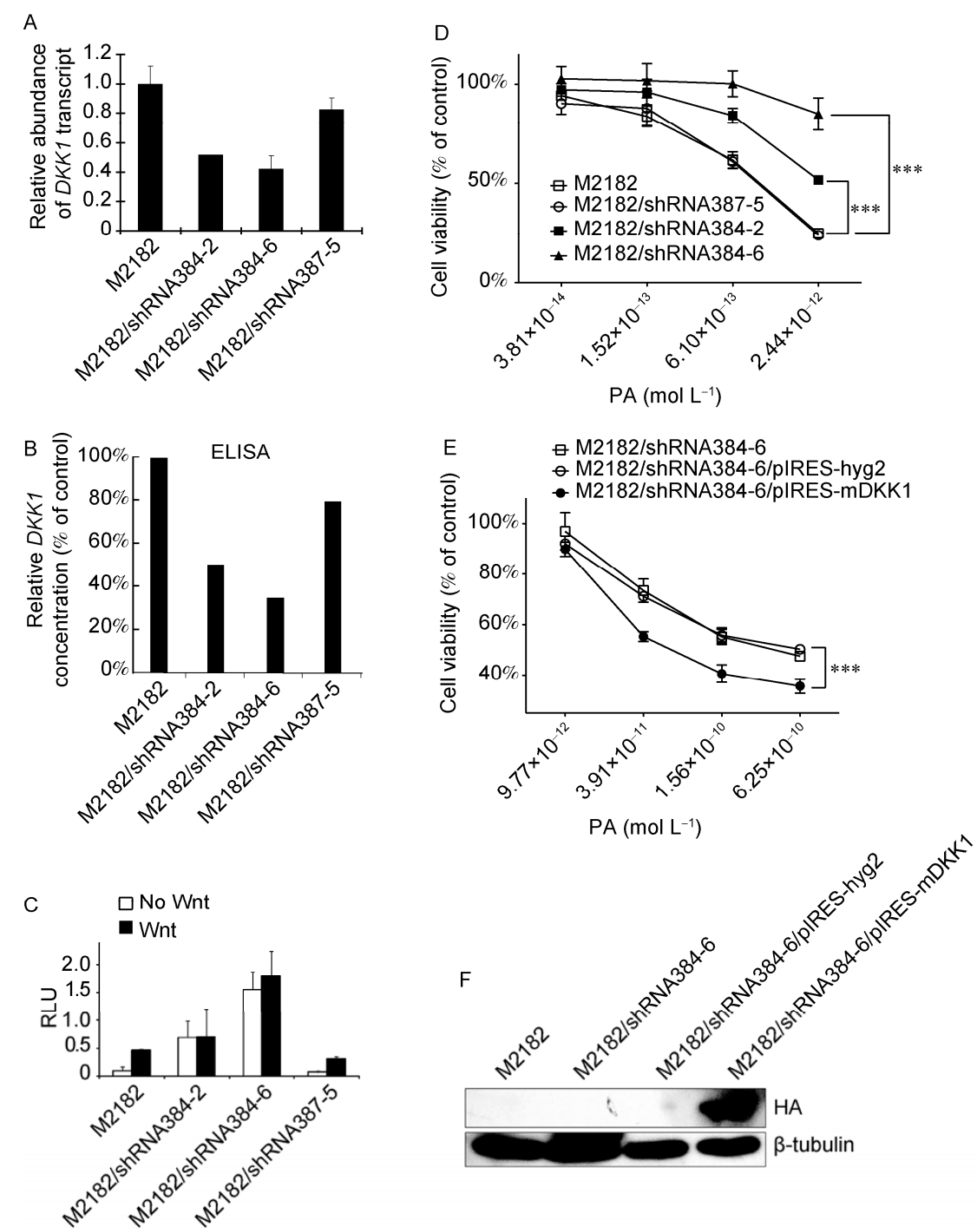

Figure 1 Effect of human DKK1 down-regulation on M2182 to PA/FP59. TRC lentiviral shRNA (TRCN0000033384) specifically targeting on human DKK1 gene was introduced into cells through viral infection. Two such clones (shRNA384-2 and -6) from M2182 were assayed for their cytotoxicity and associated gene expression level. Lentiviral shRNA (TRCN0000033387) was used as a control. A, Effect of DKK1-specific shRNA on transcript abundance. $D K K 1$ transcripts were measured by quantitative RT-PCR and normalized to $18 \mathrm{~S}$ rRNA. The primers used to amplify a region of $h D K K 1 \mathrm{mRNA}$ and $18 \mathrm{~S}$ rRNA were (5'-CCGAGGAGAAATTGAGGAAA and 5'-CCGGAGACAAACAGAACCTT) and (5'-TTTGACTCAACACGGGAAAC and 5'-ATCGCTCCACCAACTAAGAAC), respectively. Data are mean $\pm \mathrm{SD}, n=3$. B, Effect of $D K K 1$-specific shRNA on secreted DKK1 protein abundance. DKK1 protein concentration was measured by Assay Designs' human DKK1 TiterZyme Immunometric Assay (ELA) kit (Assay Design, USA). C, Effect of DKK1 deficiency on cellular response to Wnt activation in M2182/shRNA384-2 and -6. Wnt3a-stimulated Wnt signaling was assayed in cells carrying Super8XTOPflash reporter plasmid and pcDNA3.1-lacZ plasmid for normalization through transient transfection [20]. Data are mean \pm SD, $n=3$. D, Cytotoxicity assay of M2182/shRNA384-2 and -6 to PA/FP59. Data are mean $\pm \mathrm{SD}, n=6$; ***, $P<0.005$. E, Cytotoxicity assay for the effect of exogenous expression of mDKK1 in M2182/shRNA384-6 to PA/FP59; mean \pm SD, $n=6$; ***, $P<0.005$. F, Western blot analysis of exogenous expressed mouse DKK1 in M2182/shRNA384-6 was conducted as described [20]. The cells carrying corresponding cloning vectors were used as control. $\beta$-tubulin abundance was measured as an internal control

effects of interference with LRP6 activity, we observed that an shRNA-induced decrease in $D K K 1$ expression was associated with increased cell survival in the presence of toxin (Figure 1D). Reversal of increased cell survival by shRNA directed against human $D K K 1$ in $\mathrm{M} 2182$ cells was achieved by adventitious expression of mouse DKK1 in these cells (Figure 1E and F) (clone shRNA384-6), confirming that the effect is specifically a consequence of DKK1 deficiency.

\subsection{Effect of DKK1 knockout on PA-mediated toxicity}

To further determine the role of DKK1 in PA-mediated toxicity, $D K K 1$ gene knockout clones were obtained in both HEK293T and M2182 cells using the TALEN technique [36,39], which enables the introduction of double strand DNA breaks at specific chromosomal sites. Analysis of the sequence of the TALEN-targeted genome region confirmed that the selected HEK293T/DKK1 $1^{-/}$clone contained at 
least three types of indels (insertions or deletions) that caused a frame shift in the coding sequence of DKK1 (Figure 2A and B). Similarly, the M2182/DKK1 ${ }^{-1-}$ clone was confirmed to have identical 17-nt deletion in DKK1 alleles that completely disrupted gene expression (Figure 2C). The loss of DKK1 gene expression in both HEK293T and M2182 cells was functionally confirmed by the elevated basal or induced level of Wnt signaling in these clones (Figure 2D and F). Importantly, the absence of DKKI expression in both lines was associated with less sensitivity to PA/LFnDTA (Figure 2E and G), and exogenous expression of $\mathrm{m} D K K 1$, but not of the mock control (cells transfected with only the expression vector), restored normal toxin sensitivity to the HEK293T/DKK1 $1^{-/-}$clone (Figure 2D-E). Our gene knockout data confirm that DKK1 deficiency in HEK293T and M2182 cells results in decreased PA-mediated toxin lethality.

\subsection{Bidirectional effect of DKK1 expression on cell susceptibility to PA/FP59 or PA/LFnDTA}

Collectively, the above results and those reported previously [20,21] indicate that the actions of both LRP6 and its antagonist DKK1 are necessary for normal PA-mediated toxicity in HEK293T and M2182 cells. To better understand the mechanism(s) underlying such conjoint regulation by Wnt signaling proteins, we examined the effect of adventitious expression of DKK1 on naïve cells on PAmediated toxicity. By introducing a pIRES-hyg2 based construct expressing mouse DKK1 into the M2182 cell line and selecting a stably transfected pooled population using an appropriate antibiotic marker $\left(500 \mu \mathrm{g} \mathrm{mL}^{-1}\right.$ of hygromycin), we tested the effects of such overexpression on both Wnt signaling and PA-mediated toxicity. As seen in Figure $3 \mathrm{~A}$, we found by measuring beta-catenin activity that the Wnt signaling pathway is constitutively active in M2182 cells, consistent with the published effects of DKK1 on Wnt signaling mediated through its known antagonism of LRP6 [25]. Adventitious DKK1 expression in M2182 cells also reduced sensitivity to PA+FP59, enabling M2182 cells to survive normally lethal toxin concentrations (Figure 3A, right), consistent with earlier evidence that down-regulation of LRP6 in M2182 cells decreases cytotoxicity of the PA+FP59 complex [20,21].

Unlike the effects of over-expression of DKK1 in M2182 cells, such overexpression in HEK293T, HeLa and BHK revealed an increase, rather than decrease in toxin sensitivity (Figures 3B, 3C and 4, right), while still showing the expected ability of DKK1 to down-regulate either constitutive or induced Wnt signaling (Figures 3B, 3C and 4, left). Quantitative PCR analysis revealed that basal expression of DKK1 transcripts was significantly different in the above cell lines (Figure 3D, left). Additionally, this analysis showed that the abundance of DKK1 in M2182 cells was $30 \times$ and $2 \times$ greater than that in HEK293T and
HeLa cells, respectively (Figure 3D, right).

The above findings raised the possibility that differences in the level of endogenous expression of DKK1 may determine the consequences of adventitious overexpression of the gene and that overall DKK1 concentration above or below the optimal range diminishes toxicity. To test this notion, we adventitiously expressed increasing amounts of DKK1 in HEK293T, which natively expresses a low level of DKK1 (Figure 3D), by transfecting cells with increasing amounts of a DKK1 expressing plasmid (pEF-hDKK1). Whereas increasing amounts of adventitious expression of DKK1 resulted in incremental inhibition of Wnt signaling (Figure 3E), the effects of incremental DKK1 expression on PA-dependent toxicity were bidirectional (Figure 3F). Similar effects were observed in DKK1 deficient M2182/ $\mathrm{DKK}^{-1-}$ cells (Figure 3G-J). Control experiments showed no effect of DKK1 on cell viability in the absence of toxin (Figure $3 \mathrm{H})$. Collectively, our results suggest that the effect of DKK1 on cellular susceptibility to PA-mediated toxicity is both bidirectional and dependent on cell context.

Although we showed that DKK1 promoted PA-mediated toxicity of the hybrid toxin FP59 or LFnDTA, we wanted to confirm this finding for native anthrax toxin. Accordingly, we introduced pIRES-hyg2 and pEF6MycHisBsd-B-based constructs expressing human or mouse DKK1 into RAW264.7 cells, which are killed by PA/LF [40], and selected the stably transfected pooled population using appropriate antibiotic markers $\left(500 \mu \mathrm{g} \mathrm{mL}^{-1}\right.$ of hygromycin for pIRES-Hyg2 clones, and $2 \mu \mathrm{g} \mathrm{mL}^{-1}$ of Blasticidin for pEF6MycHisBsd-B clones). We observed that DKK1 expression from the introduced DKK1-overexpression constructs reduced basal Wnt signaling (Figure 5A), as expected, and that adventitious DKK1 expression in RAW264.7 cells reduced sensitivity to PA/LF, leading to cell survival at normally lethal toxin concentrations (Figure $5 \mathrm{~B})$. This result parallels to the observations we had made for M2182 cells exposed to PA+FP59. Moreover, exposure of the RAW264.7 macrophage cell line to three of seven monoclonal antibodies directed against the full-length human DKK1 decreased PA/LF toxicity in a dosedependent manner (Figure 5C). Control experiments showed that none of the seven antibodies tested affected cell viability per se, even at the highest antibody dosage $\left(20 \mu \mathrm{g} \mathrm{mL}^{-1}\right)$ tested.

\subsection{DKK1 deficiency reduces $\mathrm{PA}$ internalization in M2182 cells}

The known ability of DKK1, which is a secreted protein [41] to modulate LRP6 function, and the previously shown ability of LRP6 deficiency to reduce toxin internalization in M2182 cells [20] suggested that perturbation of the cellular DKK1 level may alter internalization of toxin. As shown in Figure 6, Western blot analysis of the lysates from M2182 cells made resistant to toxin by shRNA384-6, but not by an anti-DKK1 shRNA (i.e., shRNA387-5) that was found to 


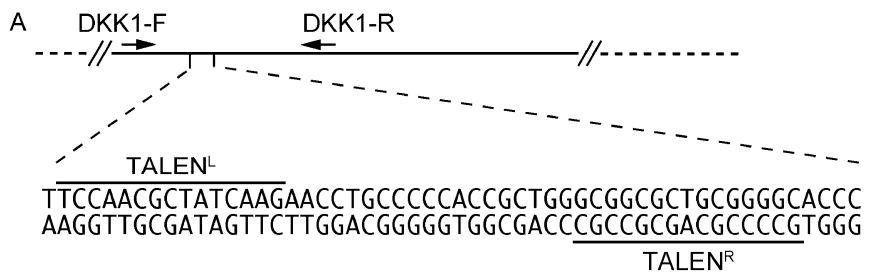

B

TTCCAACGCTATCAAGAACCTGCCCCCACCGCTGGGCGGCGCTGCGGGGACCC Wild-type

TTCCAACGCTATCAAGAACC--.--

TTCCAACGCTATCAAGAACCTGCCCCCAAC--------CTGCGGGCACCC $(\Delta 11)$

TTCCAACGCTATCAAGAACCTGCAA---------GCGGCGCTGCGGGCACCC $(\Delta 10)$

C

TTCCAACGCTATCAAGAACCTGCCCCCACCGCTGGGCGGCGCTGCGGGGCACCC Wild-type TTCCAACGCTATCAAGAACCT------------GCGCTGCGGGGCACCC $(\Delta 17)$
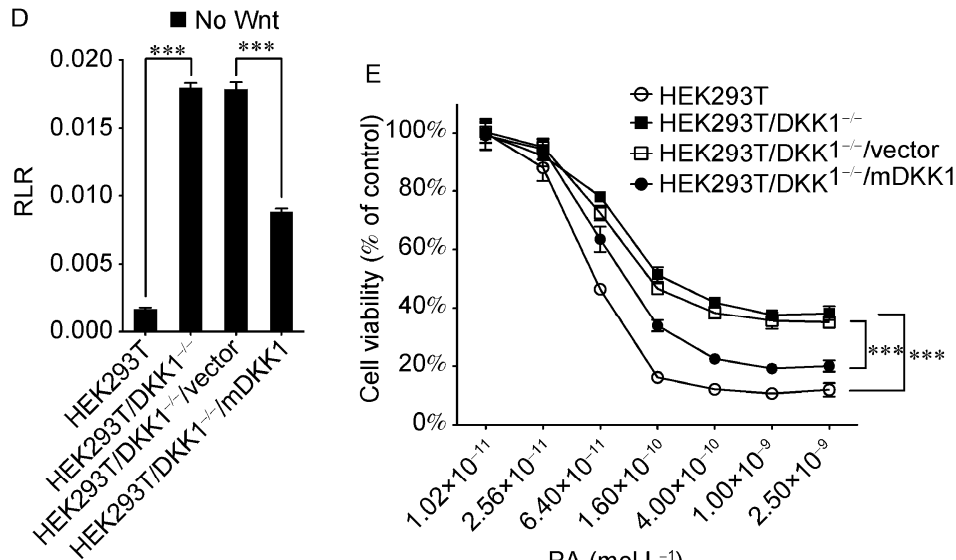

$\mathrm{PA}\left(\mathrm{mol} \mathrm{L}^{-1}\right)$
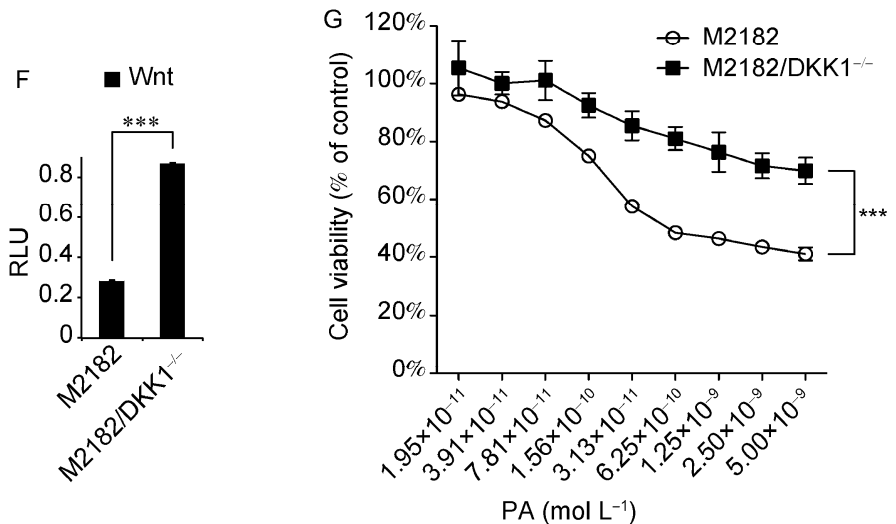

Figure 2 Effect of TALEN-mediated DKK1 knockout on cell sensitivity of HEK293T and M2182 to PA/LFnDTA. A, Partial sequence of wild-type $h D K K 1$ gene in genome containing TALENs binding regions (overlined for TALEN ${ }^{\mathrm{L}}$ and underlined for TALEN ${ }^{\mathrm{R}}$ ). DKK1-F and DKK1-R are primers used to amplify the TALEN-targeting region of $h D K K 1$ loci. B, Sequencing analysis of mutated alleles from eight randomly selected genome PCR clones (in pMD19-T vector) isolated from a single DKK1-targeting-TALEN clone (in HEK293T cells). The primers used to amplify the TALENs targeting region for sequencing analysis were 5'-CCTTCTGAGATGATGGCTCTGGGCG-3' (DKK1-F) and 5'-CCAGACGTCCAGGTACCCGCC-3' (DKK1-R). Compared with the wild-type, four clones had 20-nt deletion $(\Delta 20)$, two clones had 11-nt deletion $(\Delta 11)$, and two clones had 10-nt deletion $(\Delta 10)$. The TALENs binding sites (underlined) are highlighted. Dashes and tall letters indicate deletions and insertions, respectively. C, Sequencing analysis of mutated alleles from 10 randomly selected genome PCR clones (in pMD19-T vector) isolated from a single DKK1-targeting-TALEN clone (in M2182 cells). All 10 clones had 17-nt deletion in the TALEN-targeting region as indicated by dashes. D, Effect of DKK1 knockout and exogenous expressed mouse DKK1 on cellular response to native Wnt signaling in HEK293T/DKK1 ${ }^{-/}$and HEK293T/DKK $1^{-/} / \mathrm{mDKK} 1$ cells. Wnt signaling assay was conducted as described as in Figure 1. Data are mean $\pm \mathrm{SD}, n=3 ; * * *, P<0.005$. E, Cytotoxicity assay of HEK293T/DKK $1^{-/-}$and HEK293T/DKK $1^{-/-} / \mathrm{mDKK} 1$ to PA/LFnDTA. The cells carrying corresponding cloning vectors were used as controls. Data are mean \pm SD, $n=6$; ***, $P<0.005$ for HEK293T/DKK1 ${ }^{-/-}$(vs. HEK293T), and ***, $P<0.005$ for HEK293T/DKK1 $1^{-/} / \mathrm{mDKK} 1$ (vs. HEK293T/DKK1 $1^{-/} /$vector). F, Effect of DKK1 knockout on cellular response to native Wnt signaling in M2182 cells. Data are mean $\pm \mathrm{SD}, n=3 ; * * *, P<0.005$. G, Cytotoxicity assay of $\mathrm{M} 2182 / \mathrm{DKK} 1^{-/}$to PA/LFnDTA; mean $\pm \mathrm{SD}, n=6$; ***, $P<0.005$. 

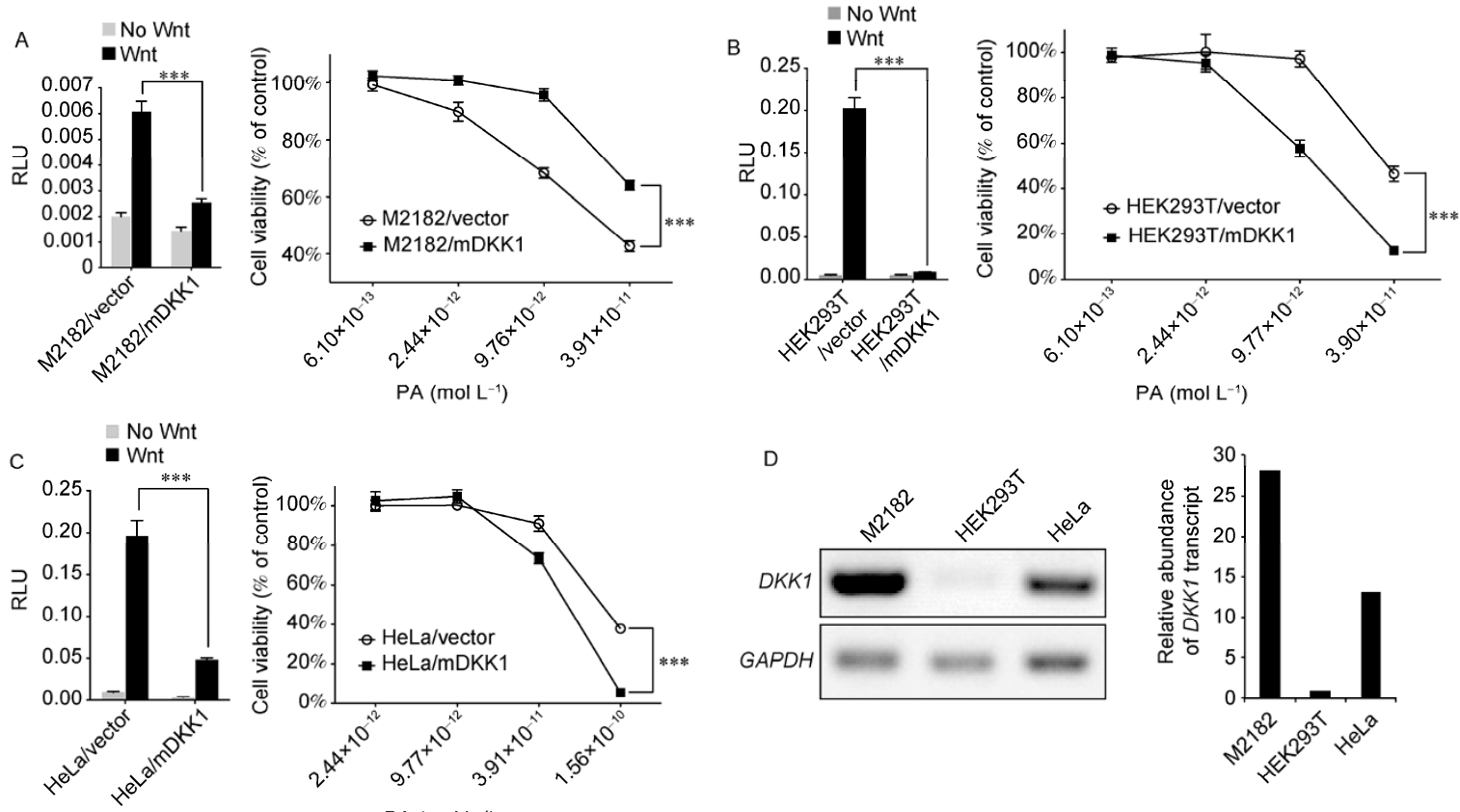

$\mathrm{PA}(\mathrm{mol} \mathrm{L}-1)$
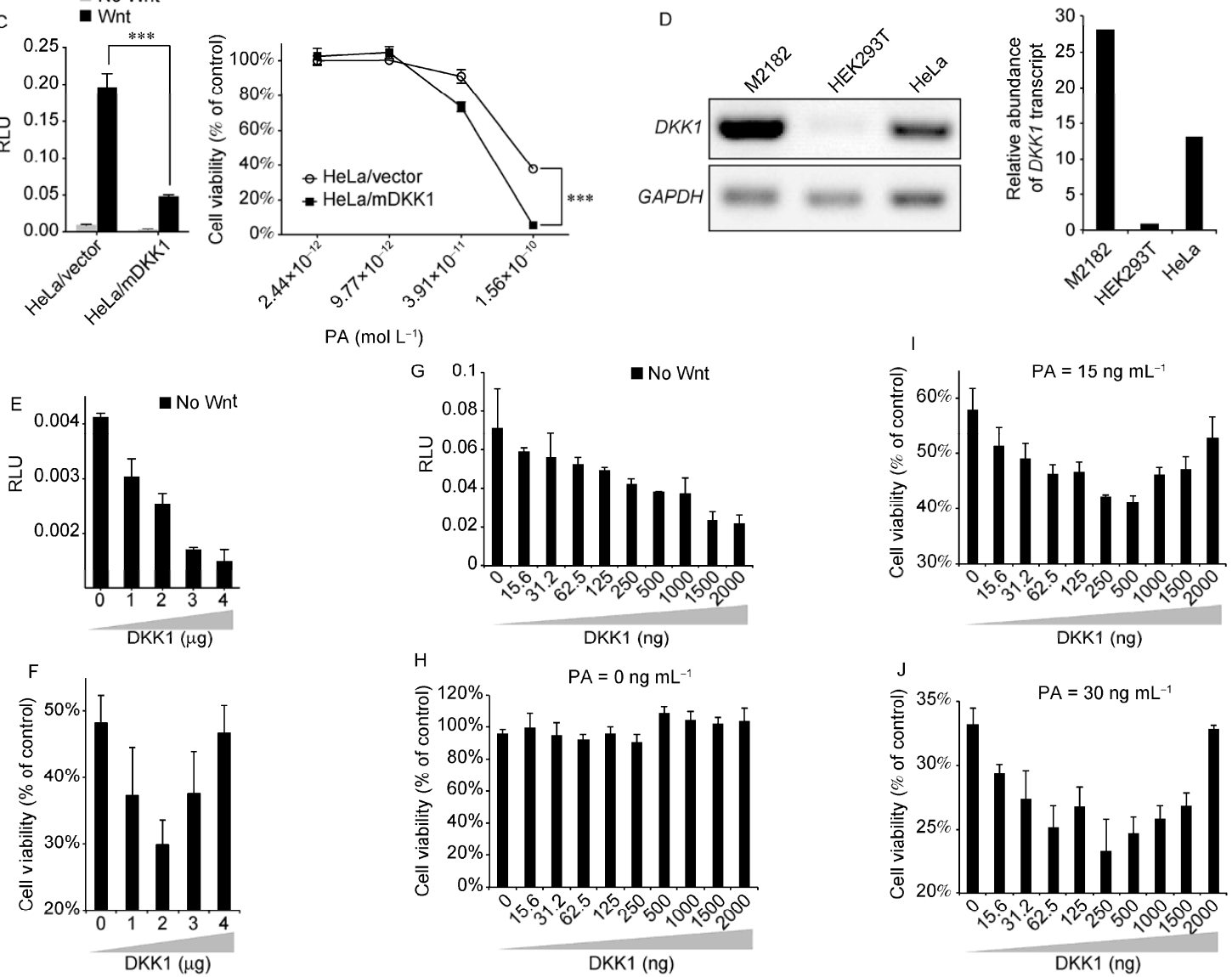

Figure 3 Bidirectional effect of adventitious expression of DKK1 on cell sensitivity to PA/LFnDTA. DKK1 genes were cloned into two kinds of expression vectors, pIRES-hyg2 and pEF6MycHisBsd-B. A-C (left), Effect of DKK1 over-expression on cellular response to Wnt activation in M2182 (A), HEK293T (B), and HeLa (C) cells. Wnt1-stimulated Wnt signaling was assayed in cells carrying Super8XTOPflash reporter plasmid and plasmid carrying SV40-Renilla luciferase for normalization through transient transfection. Data are mean $\pm \mathrm{SD}, n=3$; $* * *, P<0.005$. A-C (right), Cytotoxicity of PA/FP59 in DKK1-overexpressed M2182 (A), HEK293T (B) and HeLa (C) cells. Cells carrying corresponding cloning vectors were used as controls. Cells were seeded at a concentration of $5 \times 10^{3}$ cells/well (96-well plate), and treated with serially diluted PA and fixed concentration of FP59 (50 ng mL ( $^{-1}$ ) for two days before being assayed by MTT. Data are mean \pm SD, $n=6$; ***, $P<0.005$. D, Level of $D K K 1$ transcript in M2182, HEK293T and HeLa cells was measured by RT-PCR and normalized to GAPDH (D, left). The primers used in PCR reactions were (5'-GACCATTGACAACTACCAGCCGTAC-3' and 5'-CCTGAGGCACAGTCTGATGACC-3') for $D K K 1$, and (5'-ACGGATTTGGTCGTATTGGG-3' and 5'-CGCTCCTGGAAGATGGTGAT-3') for $G A P D H$. The relative abundance of $D K K 1$ transcript in these cells was quantified using ImageJ (http://rsbweb.nih.gov/ij/) (D, right). E and F, Effect of increasing amount of DKK1 on cellular response to native Wnt signaling (E) and cell survivability to PA/LFnDTA (F) in HEK293T cells. HEK293T cells were transfected with serially increased amount of pEF-hDKK1 plasmid DNA $(0,1,2,3,4 \mu \mathrm{g})$ using Lipofectamine 2000 . The corresponding cloning vector pEF was used to ensure that the total amount of DNA used in the transfection was equal ( $4 \mu \mathrm{g}$ in total). Forty-eight hours post transfection, cells were assessed for both the basal level of Wnt signaling (E) and the cell survivability to PA $\left(6.48 \mathrm{ng} \mathrm{mL}{ }^{-1}\right) / \mathrm{LFnDTA}\left(50 \mathrm{ng} \mathrm{mL}^{-1}\right)(\mathrm{F})$. Data are mean $\pm \mathrm{SD}, n=3(\mathrm{E})$ and $6(\mathrm{~F})$. G-J, Effect of increasing amount of DKK1 on cellular response to native Wnt signaling $(\mathrm{G})$ and cell survivability to PA/LFnDTA in M2182/DKK1 ${ }^{-/-}$cells $(\mathrm{H}-\mathrm{J}) . \mathrm{M} 2182 / \mathrm{DKK} 1^{--}$cells were transfected with serially increased amount of pEF-mDKK1 plasmid DNA $(0,15.6,31.2,62.5,125,250,500,1000,1500$, and $2000 \mathrm{ng}$ ) using X-tremeGENE HP transfection reagent. The corresponding cloning vector pEF was used to ensure that the total amount of DNA used in the transfection was equal (2000 ng in total). Forty-eight hours post transfection, cells were split into four portions. One was used to test the basal level of Wnt signaling $(\mathrm{G})$, and the other three were used to test the cell survivability to LFnDTA $\left(50 \mathrm{ng} \mathrm{mL}^{-1}\right)$ plus variable concentration of PA $(0,15$ and $30 \mathrm{ng}$ $\left.\mathrm{mL}^{-1}\right)(\mathrm{H}-\mathrm{J})$. Data are mean $\pm \mathrm{SD}, n=3(\mathrm{G})$ and $6(\mathrm{H}-\mathrm{J})$. 


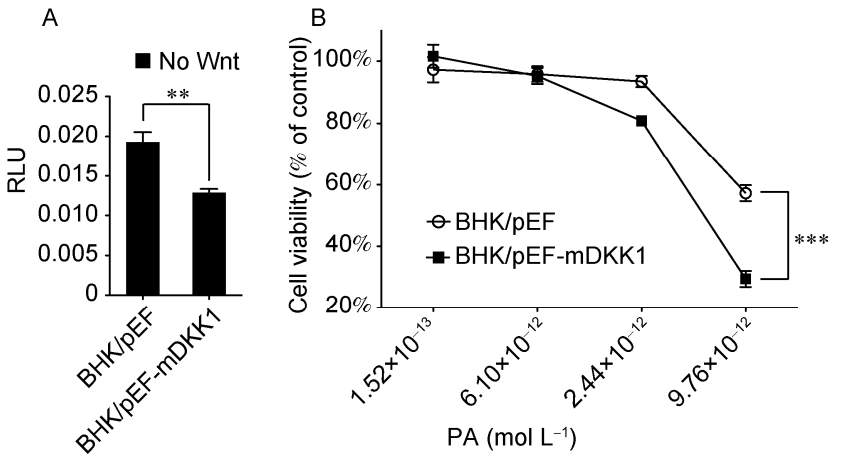

Figure 4 Effect of adventitious expression of DKK1 on cell sensitivity of BHK to PA/FP59. A, Effect of DKK1 over-expression on cellular response to native Wnt signaling in BHK cells. Data are mean $\pm \mathrm{SD}, n=3$; **, $P<0.01$. $\mathrm{B}$, Cytotoxicity of PA/FP59 in DKK1-overexpressed BHK cells. Data are mean $\pm \mathrm{SD}, n=6 ; * * *, P<0.005$.

not significantly reduce DKK1 expression (Figure 1), showed no detectable difference on $83 \mathrm{kD}$ PA monomer bound to the cell surface (Figure 6A). However, treatment of cells with the DKK1-inhibiting shRNA was associated with reduction of an SDS-resistant oligomeric form of PA that characteristically survives proteolytic treatment when cell cultures exposed to toxin complexes at $4^{\circ} \mathrm{C}$ are shifted to $37^{\circ} \mathrm{C}$ and toxin complexes are internalized (Figure 6B). Confocal fluorescence microscopy using chimeric LFEGFP [32] and PA indicated that the LF detected in the cytoplasm, but not at the cell surface, was reduced in the DKK1-knockdown clone M2182/shRNA384-6 (Figure 6C), consistent with our biochemical evidence of decreased PA internalization. We conclude that DKK1 affects anthrax toxicity by modulating internalization of the cell surface complex containing LRP6, PA, and PA receptors rather than by altering the binding of the PA to its receptors.

\subsection{DKK1 forms a ternary complex with LRP6 and Kremen2 to internalize PA-mediated toxins}

We have previously shown that LRP6 interacts with PA receptors (ANTXRs), ANTXR1/TEM8 and ANTXR2/ CMG2 [20]. Co-immunoprecipitation (co-IP) experiments showed that DKK1 is also a member of the complexes that PA forms with both of these ATRs (Figure 7A and B). In these experiments, the C-terminal Myc-tagged hDKK1 or HA-tagged mDKK1 was harvested from HEK293T cells incubated with lysates containing HA-tagged ANTXR1/ TEM8 (ANTXR1-HA) or Myc-tagged ANTXR2 $\Delta$ C/CMG$2 \Delta \mathrm{C}$ (ANTXR2 $\Delta \mathrm{C}-\mathrm{Myc}$, containing only the extracellular and transmembrane region of ANTXR2); DKK1 was detected in precipitates of ANTXR1-HA (Figure 7A, left), and ANTXR1 was observed in precipitates of DKK1- Myc (Figure 7A, right). Similarly, we observed ANTXR2 $\triangle \mathrm{C}$ in precipitates containing DKK1-HA (Figure 7B, left) and found DKK1 in precipitates containing ANTXR2 $\Delta$ C-Myc (Figure 7B, right). Although we observed no interaction between DKK1 and PA, hDKK1-Myc was able to precipitate PA through ANTXR1 (Figure 7C). In addition, the presence of PA enhanced the interaction between DKK1 and ANTXR1 (Figure 7C). This finding plus our observation in confocal microscopy that red fluorescencelabelled DKK1-Myc co-localized with internalized ANTXR2EGFP triggered by PA $\left(1 \mu \mathrm{g} \mathrm{mL}^{-1}\right)$ (Figure 7D), suggested that DKK1 is a component of PA-ANTXR1/2-LRP6 complex.

The above result, together with our data showing that DKK1 and LRP6 interact functionally to facilitate the endocytosis of anthrax toxin, led us to hypothesize that the previously described ternary complex consisting of DKK1, LRP6 and Kremen2 [26] may facilitate endocytosis of the toxin-together with its receptor $[20,21,42]$. To test this
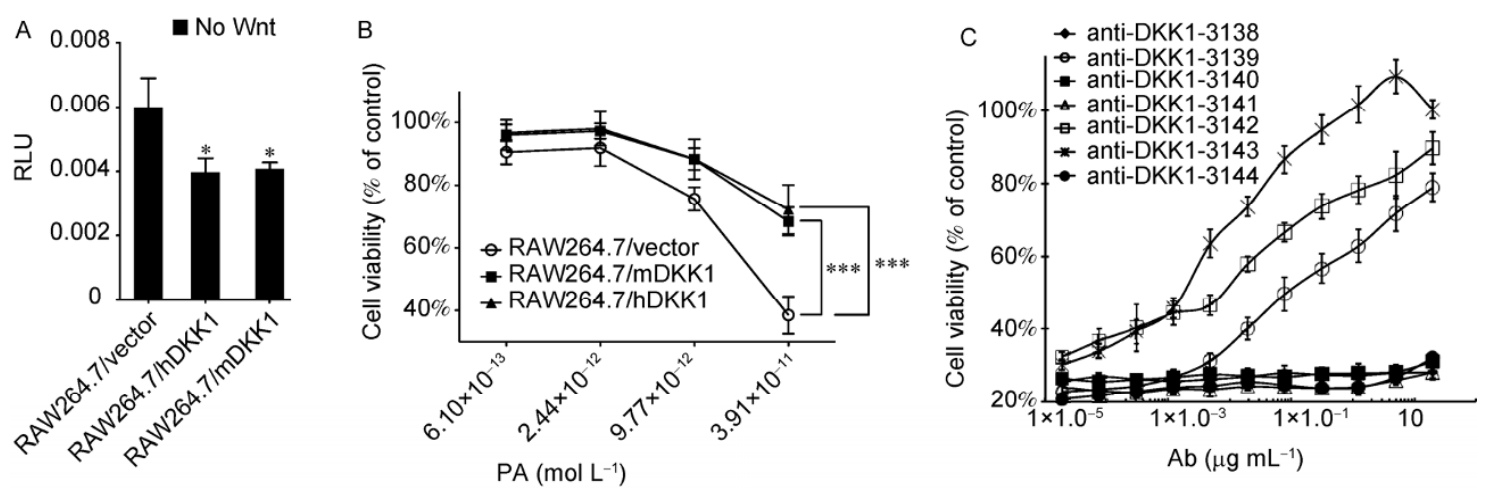

Figure 5 Effects of exogenous expression of DKK1 and anti-hDKK1 monoclonal antibodies on killing of RAW264.7 cells by PA/LF. A, Effect of DKK1 over-expression on cellular response to native Wnt signaling in RAW264.7 cells. Data are mean $\pm \mathrm{SD}, n=3 ; *, P<0.05$. B, Cytotoxicity of PA/LF in DKK1-overexpressed RAW264.7 cells. Cells carrying corresponding cloning vectors were used as controls. Data are mean \pm SD, $n=6$; $* * *, P<0.005$. C, Effect of monoclonal antibodies against hDKK1 on the sensitivity of RAW264.7 cells to PA/LF. $5 \times 10^{4} \mathrm{~mL}^{-1}$ cells of RAW264.7 were first seeded in 96 -well plates $(100 \mu \mathrm{L} /$ well) the day prior to the assay. The cells were pre-incubated with serially diluted antibodies (anti-DKK1-3138-3144) for $1 \mathrm{~h}$, followed by the addition of DMEM growth medium containing or lacking a fixed concentration of toxins (PA and $\mathrm{LF}$, each $50 \mathrm{ng} \mathrm{mL}^{-1}$ ). The plates were incubated at $37^{\circ} \mathrm{C}$ and with $10 \% \mathrm{CO}_{2}$ for $24 \mathrm{~h}$ prior to the cell viability assay as described [20]. Data are mean $\pm \mathrm{SD}, n=6$. 
A

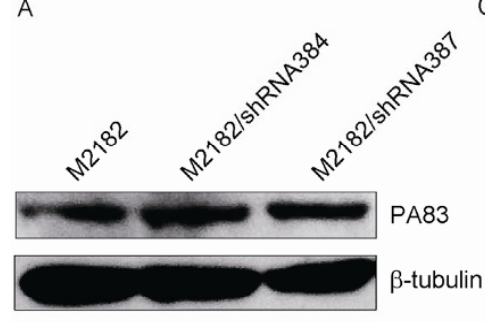

B

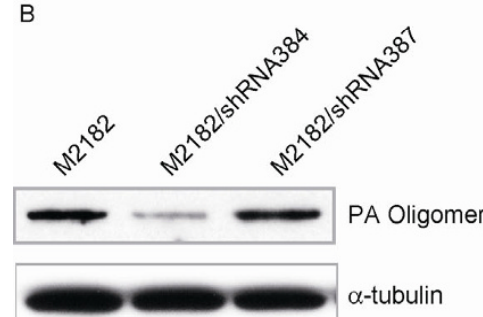

C

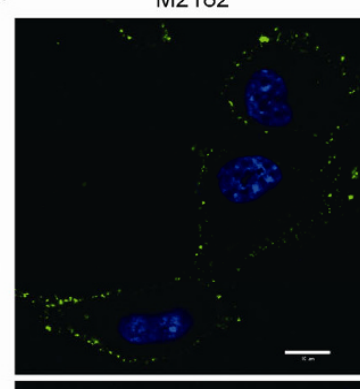

M2182/shRNA384

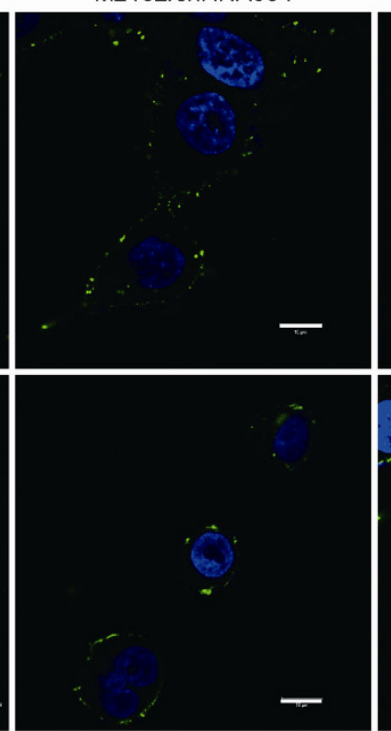

M2182/shRNA387

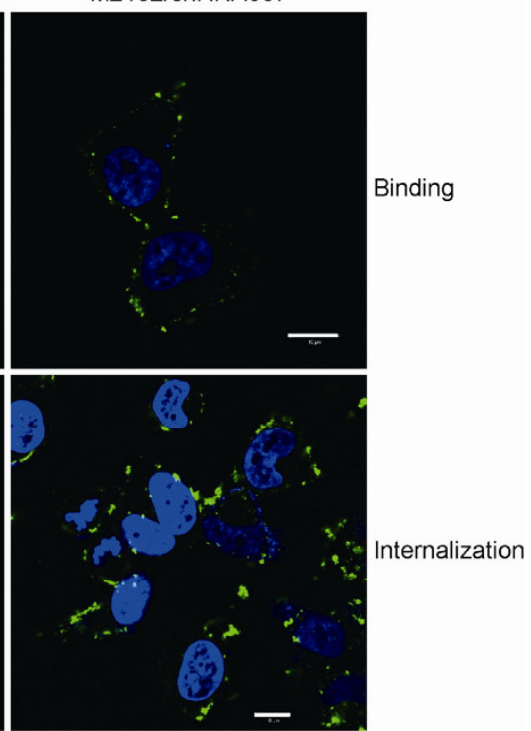

Figure 6 Effect of DKK1 deficiency in M2182 cells on PA binding and internalization. A and B, Western blot analysis of bound (A) and internalized (B) $\mathrm{PA}$ in different cells was conducted following the protocol as described [20]. PA83 is the full-length form of PA (83 kD), and the oligomer represents the heptamer of PA63. $\alpha$-tubulin or $\beta$-tubulin abundance was measured as an internal control. C, Immunofluorescence microscopy of PA/LF-EGFP binding and internalization in different cells. To monitor cell surface binding (top), cells were first treated with $\mathrm{PA} 83\left(600 \mathrm{nmol} \mathrm{L}^{-1}\right)$ for 12 min at $37^{\circ} \mathrm{C}$, washed, incubated with LF-EGFP $\left(200 \mathrm{nmol} \mathrm{\textrm {L } ^ { - 1 }}\right)$ for $2 \mathrm{~min}$ at $37^{\circ} \mathrm{C}$ and immediately washed and fixed before examined by confocal microscopy. To monitor PA/LF-EGFP internalization (bottom), cells were incubated with PA83 (600 nmol L ${ }^{-1}$ ) and LF-EGFP $\left(200 \mathrm{nmol} \mathrm{L}^{-1}\right)$ for 15 min at $37^{\circ} \mathrm{C}$ and followed by confocal microscopy [32]. Scale bar, $10 \mu \mathrm{m}$.

A

B
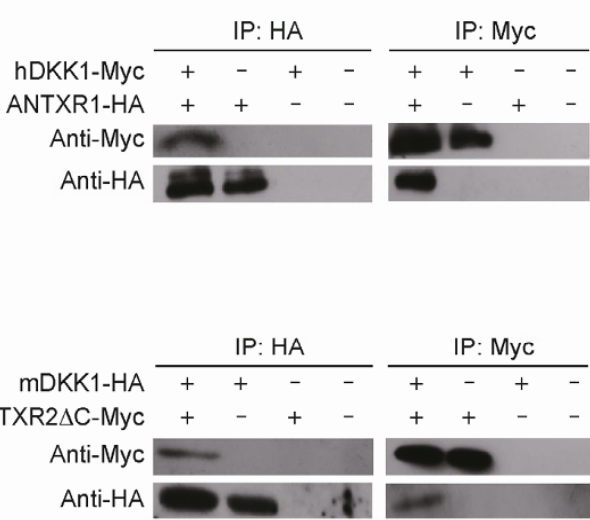

C

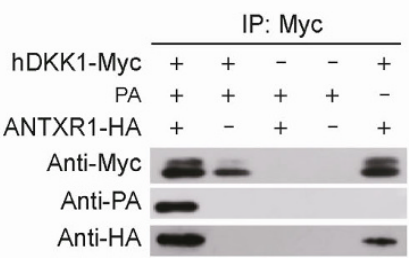

D
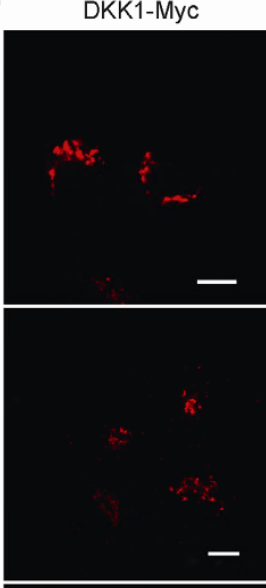

ANTXR2-EGFP
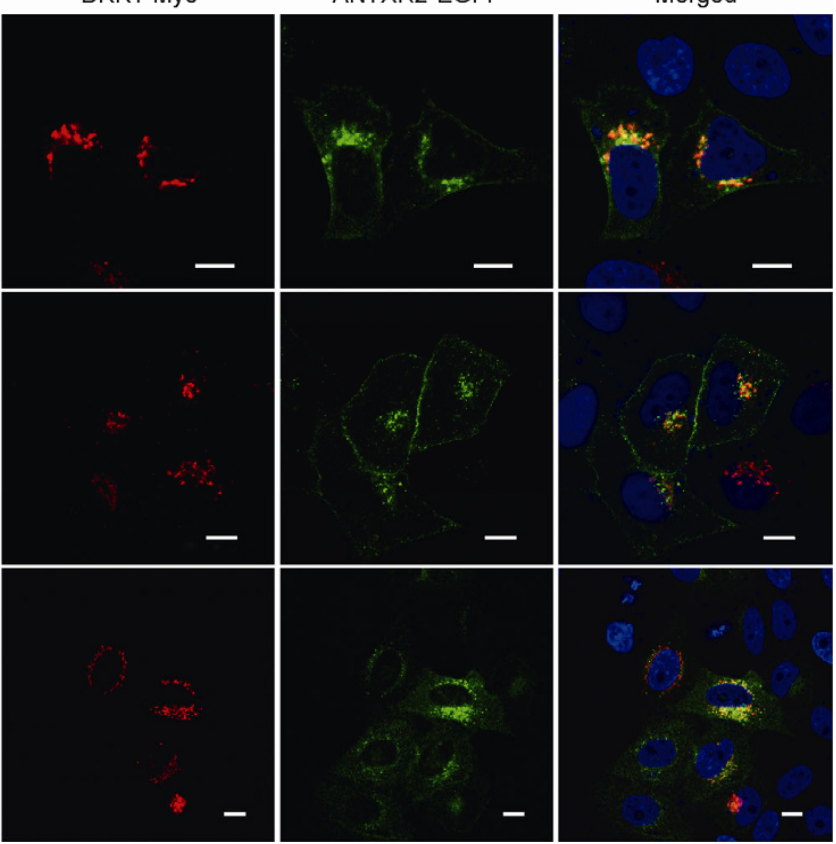

Merged

Figure 7 Binding of DKK1 to ANTXR1, ANTXR2 and PA. A, HEK293T cells were transfected with hDKK1-Myc, ANTXR1-HA, or both. Cell lysates were treated by addition of anti-HA-conjugated agarose beads (left) or anti-c-Myc-conjugated agarose beads (right). The precipitated proteins were then subjected to immunoblotting analysis probed with anti-c-Myc antibody conjugated with horseradish peroxidase (HRP) or anti-HA-HRP. B, HEK293T cells were transfected with mDKK1-HA, ANTXR2 $\triangle \mathrm{C}$-Myc, or both. Cell lysates were treated by addition of anti-HA-conjugated agarose beads (left) or anti-c-Myc-conjugated agarose beads (right). The precipitated proteins were then subjected to immunoblot analysis probed with anti-c-Myc-HRP or anti-HA-HRP. C, HEK293T cells were transfected with hDKK1-Myc, ANTXR1-HA, or both. Cell lysates were then incubated with or without PA83 on ice for $2 \mathrm{~h}$ before being mixed with anti-c-Myc-conjugated agarose beads. The precipitated proteins were then subjected to immunoblotting analysis probed with anti-c-Myc-HRP, anti-HA-HRP or anti-PA antibodies. D, Confocal microscopy images showing co-localization of DKK1-Myc (red) and ANTXR2-EGFP (green) in the presence of PA $\left(1 \mu \mathrm{g} \mathrm{mol} \mathrm{L}{ }^{-1}\right)$. Three randomly selected images were used. Scale bar, $10 \mu \mathrm{m}$. 
hypothesis, we over-expressed LRP6, Kremen2, or LRP6 plus Kremen2 in M2182 cells under two extreme situations: one in which over-expression of DKK1 was constitutive, M2182/DKK1 (Figure 8A), and the other one in which DKK1 was absent, M2182/DKK1 $1^{-/-}$(Figure 8B). In the DKK1-high-expression background, adventitious expression of LRP6 significantly decreased cell sensitivity to PA/LFnDTA, and the addition of Kremen2 had little effect. However, adventitious expression of LRP6 plus Kremen2 in the presence of abundant DKK1 made M2182 much more sensitive to the toxin (Figure 8A). In contrast, in the absence of DKK1, the adventitious expression of LRP6, Kremen2 or the combination of these two showed no effect on cell sensitivity to PA/LFnDTA (Figure 8B).

\section{Discussion}

To exert its toxic effects, anthrax toxins must first enter the host cell cytoplasm. Three cell surface proteins can serve as receptors for PA [8-10]. Although the binding of PA to only one of the receptors is sufficient for toxin entry [43-45], loss or reduction in any of the receptors decreases toxicity [8-10], suggesting that these cell surface proteins can interact functionally or physically. LRP6, initially discovered as a co-receptor for Wnt [16-18], is a compo- nent of complexes containing ANTXR1/TEM8 and/or ANTXR2/CMG2 and can promote internalization of anthrax toxin complex [20,21]. Our discovery that DKK1, a secreted LRP6 ligand and regulator [22,25], also affects anthrax toxin internalization provides additional evidence of the role of Wnt signaling proteins on anthrax toxicity.

Although all three ATRs contain VWA/I domains (von Willebrand factor type A domains, also called integrin-like domains), their sequences share only $40 \%$ overall amino acid identity and their primary biological roles in mammalian cells are highly disparate [9]. By generating ANTXR1/TEM8-, ANTXR2/CMG2-null and TEM8/CMG2 double null mice, Leppla and colleagues recently have shown that ANTXR1/TEM8 plays a relatively minor role in mediating anthrax toxicity in rodents. ANTXR1/TEM8-null mice were as susceptible as wild type mice to lethal toxin, edema toxin, or anthrax spore challenge [11].

DKK1 is a secreted protein that binds to LRP6, as well as to Kremen (Kremen1 or Kremen2), another cell surface receptor protein, and the ternary structure formed by the interaction of these three proteins triggers rapid internalization of the complex [26]-inhibiting Wnt signaling. The data presented here and previously [20] suggest that the anthrax toxin complex hijacks this ternary structure to accomplish toxin endocytosis. Increased DKK1 production in our experiments resulted in increased
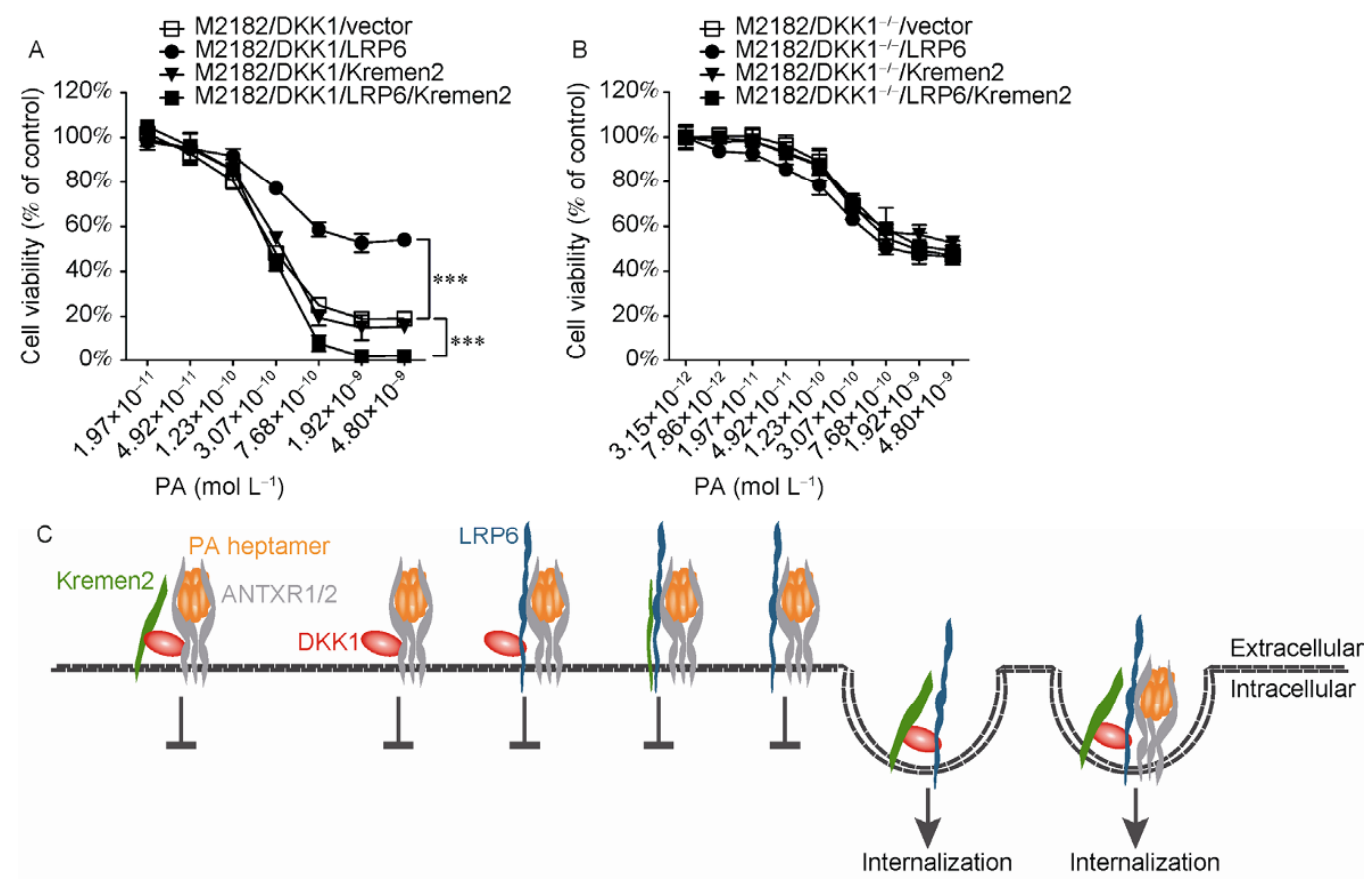

Figure 8 Effect of the ternary structure of LRP6/DKK1/Kremen2 on cell sensitivity to anthrax toxin. A and B, Effect of exogenous expression of LRP6, Kremen2 or LRP6+Kremen2 in DKK1-overexpressed M2182 (A) or DKK1-deficient M2182/DKK1 ${ }^{-/-}$(B) on the cytotoxicity of PA/LFnDTA. Cells carrying corresponding cloning vectors were used as controls. Data are mean $\pm \mathrm{SD}, n=6 ; * * *, P<0.005$. C, Model of ternary complex of LRP6/DKK1/Kremen2 in the endocytosis of anthrax toxin. Individual or any two-protein combination of LRP6, DKK1 and Kremen2 could potentially bind to the anthrax toxin complex, but none of them is capable of mediating the endocytosis process. Therefore, overexpression of DKK1, LRP6, or any two-protein combination of LRP6, DKK1 and Kremen2 may cause dominant-negative effect, depending on the basal level of these three proteins. Only the complete form of the ternary complex is fully functional to internalize PA-ANTXR1/2-LF/EF, and this ternary complex could undergo internalization by itself [26]. 
antagonism of Wnt signaling, as has been reported previously. However, the effects of such increased production on toxin sensitivity differed among the cell lines tested and were shown to be dependent on the extent of overproduction in at least two cell types. Similarly, whereas increased antagonism of LRP6-mediated Wnt signaling by up-regulation of DKK1 increased toxin lethality in HeLa, HEK293T and BHK cells, the reverse was true in M2182 and RAW267.4 macrophages. Collectively, these findings indicate that the effects of DKK1 antagonism of LRP6 are not congruent with the effects on Wnt signaling — which can also be bidirectional for a given DKK1 perturbation.

It has been reported that propeller domain 3 of LRP6 plays a dominant role in binding to DKK1 [26,46]. However, DKK1 has also been shown to bind to the first propeller domain of LRP6, and monoclonal antibody targeting on this region completely protected LRP6 from DKK1-mediated internalization [47]. Study of crystal structure revealed that the C-terminal domain of DKK1 binds to the top surface of the third propeller domain of LRP6, as well as its first propeller domain [48]. LRP6 has been shown to interact with both PA receptors, ATRs [20]. Similarly, DKK1 was found to be a component of complexes of PA with ANTXR1/TEM8 and ANTXR2/ MG2. This finding is not surprising given known ability of LRP6 to interact with DKK1 [49]. However, whether DKK1 interacts with ATRs through LRP6 or conversely, whether DKK1 serves as a bridge between LRP6 and PA receptors, is not currently known.

Anthrax toxin triggers endocytosis of its receptors via a lipid raft-mediated process [43], and PA treatment was found to be able to recruit LRP6 protein from detergent soluble fractions to detergent-resistant membrane (DRM), mimicking the process of ATRs upon PA addition [21]. Interestingly, LRP6 was found present in lipid raft microdomains [50], and DKK1 treatment is able to remove LRP6 from the lipid raft [51]. Moreover, the entry of anthrax toxin proceeds mainly through a clathrin-dependent pathway because PA internalization is dependent on the actions of dynamin and Eps15 [43]. Intriguingly, DKK1-induced internalization of LRP6 is also dependent on clathrin, and the knockdown of clathrin was able to suppress the DKK1-dependent inhibition of Wnt signaling [52]. DKK1 belongs to a protein family that contains four members. Among them, both DKK2 and DKK4 can also bind to LRP6, although with lower affinity than DKK1, and inhibit Wnt signaling $[41,53,54]$. Whether the DKK2 and DKK4 proteins also participate in anthrax toxin endocytosis, and whether there are other secreted factors beyond DKK family proteins that can affect anthrax toxin uptake is unknown.

Consistent with earlier evidence that LRP6 promotes PA uptake [20,21], antagonism of LRP6 function by overexpression of DKK1 reduced toxin sensitivity in M2182 and RAW267.4 cells. However, such enhanced antagonism of
LRP6 function, as measured by a decrease in Wnt signaling, sensitized certain cell lines to PA/FP59, including HeLa, HEK293T and BHK cells (this report), suggesting that a decrease in LRP6 functionality in cells undergoing constitutive Wnt signaling did not significantly decrease availability of LRP6 for internalization of toxin. While providing additional evidence that Wnt signaling pathway components have important roles in toxin endocytosis, our findings also show that anthrax toxicity is independent of Wnt signaling per se.

The effects of perturbation of DKK1 production and consequently on its antagonism of LRP6 function in different cell types may reflect possible differences of DKK1/LRP6 ratio, which may in turn be influenced by cell type-specific differences in the extent of use of LRP6 for autocrine Wnt signaling or the production of other proteins that affect toxin entry (e.g., ARAP3; Lu et al.). The bidirectional effect of DKK1 overproduction observed in HEK293T cells and M2182/DKK ${ }^{-/}$is reminiscent of the role of DKK2 in LRP-mediated signaling, where the LRP6 ligand can act as either an inhibitor or an activator of the Wnt pathway, depending on the cellular context (i.e., the presence or absence of Kremen2) [55]. Kremens enhance Wnt signaling by maintaining LRP5/6 at the plasma membrane in the absence of DKK1, while they inhibit Wnt signaling by promoting the endocytosis of LRP5/6 in the presence of DKK1 [24].

Importantly, using TALEN technology, we were able to knock out DKK1 gene expression in both HEK293T and M2182 cells. The complete loss of function of DKK1 confirmed its important role in anthrax toxicity. In addition, from the results of expressing DKK1, LRP6 or Kremen2, either individually or in combination, in high- or lowDKK1-expression M2182 cells, we demonstrated that (i) Kremen2 significantly increased cell sensitivity in high DKK1/LRP6 background; (ii) LRP6 significantly increased cell sensitivity in high DKK1/Kremen2 background; (iii) overexpression of LRP6 plus DKK1 greatly decreased cell sensitivity to PA-mediated toxicity, a dominant-negative effect in comparison with the result of overexpression of LRP6/DKK1/Kremen2; and, (iv) effects of LRP6 and/or Kremen2 on PA-mediated toxicity were dependent on DKK1. We therefore propose a working model in which the ternary structure, consisting of DKK1-LRP6-Kremen2, promotes the internalization of PA-ANTXR1/2-LF/EF to exert their toxic effect. It was reported that the association of DKK1, LRP6 and Kremen2 triggers rapid internalization of this ternary complex [26]. Overexpression of DKK1, LRP6, or any two-protein combination of LRP6, DKK1 and Kremen 2 may cause dominant-negative effect by competing the ternary complex to bind to the anthrax toxin complex without mediating the endocytosis of the latter (Figure 8C), possibly explaining why both up- and down-regulation of DKK1 could reduce cell's sensitivity to the toxin.

Worthy of special mention is the finding that even the 
complete loss of DKK1 in TALEN-mediated knockout cells did not make cells completely resistant to PA-mediated toxicity. Similarly, the effects of decreased LRP6 function on anthrax toxicity have been controversial [20,21,56,57], and it has been suggested that differences in results obtained in different laboratories may reflect variation in the type of cells tested [56,57]. We conclude from this finding that there are multiple mechanisms for toxin entry, as suggested by evidence that at least three cell surface proteins capable of interacting with PA have been identified [8-10]. Although a central role of ANTXR2/CMG2, which binds to PA more tightly than other receptors [58,59], has been shown for anthrax toxin lethality in mice [11], receptor expression is known to differ in different cell types $[8,9,50,59]$. Additionally, knockout of ANTXR1/TEM8 in HeLa cells abolished susceptibility to PA/LFnDTA, while the knockout of ANTXR2/CMG2 in HeLa cells had no effect at all [60]. On the contrary, knockout of ANTXR2/ CMG2 in HEK293T cells completely abolished susceptibility to PA/LFnDTA, while the knockout of ANTXR1/ TEM8 in HEK293T cells had no effect [60]. Interestingly, a recent publication by Leppla and colleagues [61] showed that LT and ET induced lethality are different on distinct cell types.

We thank S. Leppla (National Institute of Allergy and Infectious Diseases, $N I H$ ) for kind gifts of reagents, R.J. Collier (Harvard Medical School) for the plasmid pET-15b-LFNDTA, P. Chen (Peking University) for LF-EGFP protein, and Christine Tan, J. Michael Elliot, and Yan Gong (Genentech) for DKK1 antibody production and initial characterization. These studies were supported in part by the National Natural Science Foundation of China (30770465, 31070115), the National Basic Research Program of China (2010CB911800), and the Peking-Tsinghua Center for Life Sciences (to WenSheng Wei), and by an award (HDTRA1-06-C-0039) from the US Defense Threat Reduction Agency (to Stanley N. Cohen). The funders had no role in study design, data collection and analysis, decision to publish, or preparation of the manuscript.

1 Leppla SH. Anthrax toxin edema factor: a bacterial adenylate cyclase that increases cyclic amp concentrations of eukaryotic cells. Proc Natl Acad Sci USA, 1982, 79: 3162-3166

2 Young JA, Collier RJ. Anthrax toxin: receptor-binding, internalization, pore formation, and translocation. Annu Rev Biochem, 2007, 76: 243-265

3 Baldari CT, Tonello F, Paccani SR, Montecucco C. Anthrax toxins: a paradigm of bacterial immune suppression. Trends Immunol, 2006, 27: 434-440

4 Vitale G, Pellizzari R, Recchi C, Napolitani G, Mock M, Montecucco C. Anthrax lethal factor cleaves the N-terminus of MAPKKs and induces tyrosine/threonine phosphorylation of MAPKs in cultured macrophages. Biochem Biophys Res Commun, 1998, 248: 706-711

5 Duesbery NS, Webb CP, Leppla SH,Gordon VM, Klimpel KR, Copeland TD, Ahn NG, Oskarsson MK, Fukasawa K, Paull KD, Vande Woude GF. Proteolytic inactivation of MAP-kinase-kinase by anthrax lethal factor. Science, 1998, 280: 734-737

6 Vitale G, Bernardi L, Napolitani G, Mock M, Montecucco C. Susceptibility of mitogen-activated protein kinase kinase family members to proteolysis by anthrax lethal factor. Biochem J, 2000, 352(Pt 3): 739-745

7 Firoved AM, Miller GF, Moayeri M, Kakkar R, Shen Y, Wiggins JF, McNally EM, Tang WJ, Leppla SH. Bacillus anthracis edema toxin causes extensive tissue lesions and rapid lethality in mice. Am J Pathol, 2005, 167: 1309-1320

8 Bradley KA, Mogridge J, Mourez M, Collier RJ, Young JA. Identification of the cellular receptor for anthrax toxin. Nature, 2001, 414: $225-229$

9 Scobie HM, Rainey GJ, Bradley KA, Young JA. Human capillary morphogenesis protein 2 functions as an anthrax toxin receptor. Proc Natl Acad Sci USA, 2003, 100: 5170-5174

10 Martchenko M, Jeong SY, Cohen SN. Heterodimeric integrin complexes containing beta1-integrin promote internalization and lethality of anthrax toxin. Proc Natl Acad Sci USA, 2010, 107: 15583-15588

11 Liu S, Crown D, Miller-Randolph S, Moayeri M, Wang H, Hu H, Morley T, Leppla SH. Capillary morphogenesis protein-2 is the major receptor mediating lethality of anthrax toxin in vivo. Proc Natl Acad Sci USA, 2009, 106: 12424-12429

12 Park JM, Greten FR, Li ZW, Karin M. Macrophage apoptosis by anthrax lethal factor through p38 map kinase inhibition. Science, 2002, 297: 2048-2051

13 Arora N, Klimpel KR, Singh Y, Leppla SH. Fusions of anthrax toxin lethal factor to the ADP-ribosylation domain of pseudomonas exotoxin A are potent cytotoxins which are translocated to the cytosol of mammalian cells. J Biol Chem, 1992, 267: 15542-15548

14 Arora N, Leppla SH. Residues 1-254 of anthrax toxin lethal factor are sufficient to cause cellular uptake of fused polypeptides. J Biol Chem, 1993, 268: 3334-3341

15 Blanke SR, Milne JC, Benson EL, Collier RJ. Fused polycationic peptide mediates delivery of diphtheria toxin a chain to the cytosol in the presence of anthrax protective antigen. Proc Natl Acad Sci USA, 1996, 93: 8437-8442

16 Wehrli M, Dougan ST, Caldwell K, O'Keefe L, Schwartz S, Vaizel-Ohayon D, Schejter E, Tomlinson A, DiNardo S. Arrow encodes an ldl-receptor-related protein essential for wingless signalling. Nature, 2000, 407: 527-530

17 Tamai K, Semenov M, Kato Y, Spokony R, Liu C, Katsuyama Y, Hess F, Saint-Jeannet JP, He X. Ldl-receptor-related proteins in Wnt signal transduction. Nature, 2000, 407: 530-535

18 Pinson KI, Brennan J, Monkley S, Avery BJ, Skarnes WC. An LDL-receptor-related protein mediates Wnt signalling in mice. Nature, 2000, 407: 535-538

19 Lu Q, Wei W, Kowalski PE, Chang AC, Cohen SN. EST-based genome-wide gene inactivation identifies ARAP3 as a host protein affecting cellular susceptibility to anthrax toxin. Proc Natl Acad Sci USA, 2004, 101: 17246-17251

20 Wei W, Lu Q, Chaudry GJ, Leppla SH, Cohen SN. The LDL receptor-related protein LRP6 mediates internalization and lethality of anthrax toxin. Cell, 2006, 124: 1141-1154

21 Abrami L, Kunz B, Deuquet J, Bafico A, Davidson G, van der Goot FG. Functional interactions between anthrax toxin receptors and the Wnt signalling protein LRP6. Cell Microbiol, 2008, 10: 2509-2519

22 Semenov MV, Tamai K, Brott BK, Kühl M, Sokol S, He X. Head inducer Dickkopf-1 is a ligand for Wnt coreceptor LRP6. Curr Biol, 2001, 11: 951-961

23 Semenov MV, Zhang X, He X. Dkk1 antagonizes wnt signaling without promotion of LRP6 internalization and degradation. J Biol Chem, 2008, 283: 21427-21432

24 Cselenyi CS, Lee E. Context-dependent activation or inhibition of Wnt-beta-catenin signaling by kremen. Sci Signal, 2008, 1: pe10

25 Mao B, Wu W, Li Y, Hoppe D, Stannek P, Glinka A, Niehrs C. LDL-receptor-related protein 6 is a receptor for Dickkopf proteins. Nature, 2001, 411: 321-325

26 Mao B, Wu W, Davidson G, Marhold J, Li M, Mechler BM, Delius H, Hoppe D, Stannek P, Walter C, Glinka A, Niehrs C. Kremen proteins are dickkopf receptors that regulate Wnt/beta-catenin signalling. Nature, 2002, 417: 66-667

27 Bourhis E, Tam C, Franke Y, Bazan JF, Ernst J, Hwang J, Costa M, Cochran AG, Hannoush RN. Reconstitution of a frizzled8-Wnt3aLRP6 signaling complex reveals multiple Wnt and Dkk1 binding sites on LRP6. J Biol Chem, 2010, 285: 9172-9179 
28 Bourhis E, Wang W, Tam C, Hwang J, Zhang Y, Spittler D, Huang OW, Gong Y, Estevez A, Zilberleyb I, Rouge L, Chiu C, Wu Y, Costa M, Hannoush RN, Franke Y, Cochran AG. Wnt antagonists bind through a short peptide to the first beta-propeller domain of LRP5/6. Structure, 2011, 19: 1433-1442

29 Jackson-Cook C, Bae V, Edelman W, Brothman A, Ware J. Cytogenetic characterization of the human prostate cancer cell line P69SV40T and its novel tumorigenic sublines M2182 and M15. Cancer Genet Cytogenet, 1996, 87: 14-23

30 Godbey WT, Barry MA, Saggau P, Wu KK, Mikos AG. Poly(ethylenimine)-mediated transfection: a new paradigm for gene delivery. $\mathrm{J}$ Biomed Mater Res, 2000, 51: 321-328

31 Follenzi A, Ailles LE, Bakovic S, Geuna M, Naldini L. Gene transfer by lentiviral vectors is limited by nuclear translocation and rescued by HIV-1 pol sequences. Nat Genet, 2000, 25: 217-222

32 Zornetta I, Brandi L, Janowiak B, Dal Molin F, Tonello F, Collier RJ, Montecucco C. Imaging the cell entry of the anthrax oedema and lethal toxins with fluorescent protein chimeras. Cell Microbiol, 2010, 12: $1435-1445$

33 Harlow E, Lane D. Using Antibodies: A Laboratory Manual. Plainview: Cold Spring Harbor Lab Press, 1999

34 Leppla SH. Production and purification of anthrax toxin. Methods Enzymol, 1988, 165: 103-116

35 Milne JC, Blanke SR, Hanna PC, Collier RJ. Protective antigenbinding domain of anthrax lethal factor mediates translocation of a heterologous protein fused to its amino- or carboxy-terminus. Mol Microbiol, 1995, 15: 661-666

36 Yang J, Yuan P, Wen D, Sheng Y, Zhu S, Yu Y, Gao X, Wei W. Ultimate system for rapid assembly of customized tal effectors. PLoS ONE, 2013, 8: e75649

37 Veeman MT, Slusarski DC, Kaykas A, Louie SH, Moon RT. Zebrafish prickle, a modulator of noncanonical Wnt/Fz signaling, regulates gastrulation movements. Curr Biol, 2003, 13: 680-685

38 Willert K, Nusse R. Beta-catenin: a key mediator of Wnt signaling. Curr Opin Genet Dev, 1998, 8: 95-102

39 Yang J, Zhang Y, Yuan P, Zhou Y, Cai C, Ren Q, Wen D, Chu C, Qi H, Wei W. Complete decoding of tal effectors for DNA recognition. Cell Res, 2014, doi: 10.1038/cr.2014.1019

40 Hanna PC, Acosta D, Collier RJ. On the role of macrophages in anthrax. Proc Natl Acad Sci USA, 1993, 90: 10198-10201

41 Glinka A, Wu W, Delius H, Monaghan AP, Blumenstock C, Niehrs C. Dickkopf-1 is a member of a new family of secreted proteins and functions in head induction. Nature, 1998, 391: 357-362

42 Jeong SY, Martchenko M, Cohen SN. Calpain-dependent cytoskeletal rearrangement exploited for anthrax toxin endocytosis. Proc Natl Acad Sci USA, 2013, 110: E4007-4015

43 Abrami L, Liu S, Cosson P, Leppla SH, van der Goot FG. Anthrax toxin triggers endocytosis of its receptor via a lipid raft-mediated clathrin-dependent process. J Cell Biol, 2003, 160: 321-328

44 Bann JG, Cegelski L, Hultgren SJ. LRP6 holds the key to the entry of anthrax toxin. Cell, 2006, 124: 1119-1121

45 Liu S, Leppla SH. Cell surface tumor endothelium marker 8 cytoplasmic tail-independent anthrax toxin binding, proteolytic processing, oligomer formation, and internalization. J Biol Chem, 2003, 278: 5227-5234

46 Zhang Y, Wang Y, Li X, Zhang J, Mao J, Li Z, Zheng J, Li L, Harris $\mathrm{S}, \mathrm{Wu}$ D. The LRP5 high-bone-mass G171V mutation disrupts LRP5 interaction with Mesd. Mol Cell Biol, 2004, 24: 4677-4684

47 Binnerts ME, Tomasevic N, Bright JM, Leung J, Ahn VE, Kim KA, Zhan X, Liu S, Yonkovich S, Williams J, Zhou M, Gros D, Dixon M, Korver W, Weis WI, Abo A. The first propeller domain of LRP6 regulates sensitivity to Dkk1. Mol Biol Cell, 2009, 20: 3552-3560

48 Cheng Z, Biechele T, Wei Z, Morrone S, Moon RT, Wang L, Xu W. Crystal structures of the extracellular domain of LRP6 and its complex with Dkk1. Nat Struct Mol Biol, 2011, 18: 1204-1210

49 Bafico A, Liu G, Yaniv A, Gazit A, Aaronson SA. Novel mechanism of Wnt signalling inhibition mediated by Dickkopf-1 interaction with LRP6/arrow. Nat Cell Biol, 2001, 3: 683-686

50 Hynes RO. Integrins: bidirectional, allosteric signaling machines. Cell, 2002, 110: 673-687

51 Sakane H, Yamamoto H, Kikuchi A. LRP6 is internalized by Dkk1 to suppress its phosphorylation in the lipid raft and is recycled for reuse. J Cell Sci, 2010, 123: 360-368

52 Yamamoto H, Sakane H, Yamamoto H, Michiue T, Kikuchi A. Wnt3a and Dkk1 regulate distinct internalization pathways of LRP6 to tune the activation of beta-catenin signaling. Dev Cell, 2008, 15: 37-48

53 Krupnik VE, Sharp JD, Jiang C, Robison K, Chickering TW, Amaravadi L, Brown DE, Guyot D, Mays G, Leiby K, Chang B, Duong T, Goodearl AD, Gearing DP, Sokol SY, McCarthy SA. Functional and structural diversity of the human dickkopf gene family. Gene, 1999, 238: 301-313

54 Mao B, Niehrs C. Kremen2 modulates Dickkopf2 activity during Wnt/LRP6 signaling. Gene, 2003, 302: 179-183

55 Brott BK, Sokol SY. Regulation of Wnt/LRP signaling by distinct domains of Dickkopf proteins. Mol Cell Biol, 2002, 22: 6100-6110

56 Young JJ, Bromberg-White JL, Zylstra C, Church JT, Boguslawski E, Resau JH, Williams BO, Duesbery NS. LRP5 and LRP6 are not required for protective antigen-mediated internalization or lethality of anthrax lethal toxin. PLoS Pathog, 2007, 3: e27

57 Ryan PL, Young JA. Evidence against a human cell-specific role for LRP6 in anthrax toxin entry. PLoS ONE, 2008, 3: e1817

58 Wigelsworth DJ, Krantz BA, Christensen KA, Lacy DB, Juris SJ, Collier RJ. Binding stoichiometry and kinetics of the interaction of a human anthrax toxin receptor, CMG2, with protective antigen. J Biol Chem, 2004, 279: 23349-23356

59 Scobie HM, Thomas D, Marlett JM, Destito G, Wigelsworth DJ, Collier RJ, Young JA, Manchester M. A soluble receptor decoy protects rats against anthrax lethal toxin challenge. J Infect Dis, 2005, 192: 1047-1051

60 Zhou Y, Zhu S, Cai C, Yuan P, Li C, Huang Y, Wei W. High-throughput screening of a CRISPR/Cas9 library for functional genomics in human cells. Nature, 2014, doi: 10.1038/nature13166

61 Liu S, Zhang Y, Moayeri M, Liu J, Crown D, Fattah RJ, Wein AN, Yu ZX, Finkel T, Leppla SH. Key tissue targets responsible for anthrax-toxin-induced lethality. Nature, 2013, 501: 63-68

Open Access This article is distributed under the terms of the Creative Commons Attribution License which permits any use, distribution, and reproduction in any medium, provided the original author(s) and source are credited. 